\title{
A Changing Society - Perceptions of Health Needs for Non-Metropolitan Seniors and Baby Boomers in Retirement
}

\author{
Sandra Nagel Beebe \\ Southern Illinois University Carbondale
}

\begin{abstract}
The purpose of this study was to assess perceptions of seniors of their current health needs and to compare them with baby boomers' perceptions future health needs as they begin entering the senior age bracket in 2011. The focus groups were comprised of male and female seniors or baby boomer participants. The focus group sessions were conducted to collect data concerning perceptions of seniors and baby boomers preference for nomenclature and senior health care needs in retirement. The sessions were transcribed by the court reporters, the moderator, and the non-verbal information recorded by trained observers. The ten, approximately 60 -minute sessions were audiotape recorded. The transcriptions were analyzed using content analysis. Key findings from the study identified the terms of choice for individuals 65 and over were "seniors/senior citizens" with "mature" and "elderly" also commonly suggested. Similar findings evolved from the seniors and baby boomers regarding their perceptions for health needs in retirement. Eight themes evolved with numerous sub-categories. The themes included: 1) prescription drug plans, 2) insurance issues, 3) government programs, 4) transportation issues, 5) accessibility of services or doctors, 6) retirement planning, 7) attitudes, and 8) rating one's health. During the focus group sessions, these themes consistently overlapped concern for health needs in retirement. The most important aspect from all session was the theme: attitude. Having a positive attitude about one's health is what will contribute to staying healthy. Participants recommended eating healthy, exercising, abstaining from smoking, and reducing stress were important considerations for preparing and living a healthy retirement.
\end{abstract}

(C) 2004 Californian Journal of Health Promotion. All rights reserved.

Keywords: baby boomers, seniors, retirement, health needs

\section{Introduction}

As our nation enters the 21st century, we are facing rapid demographic changes. We are changing from a youthful nation into an older nation. Statistics show the number and proportion for individuals 65 years of age and older have grown faster than any other United States segment. At the turn of the twentieth century, 4.1 percent of the nation was 65 years of age and older (U.S. Census Bureau, 1993). By 1950, 8.1 percent were over 65 years of age, 1960, 9.2 percent, and 1990, 12.6 percent. According to the U.S. Census Bureau (2001), individuals 65 years of age and older decreased to 12.4 percent. The difference was not a decrease in seniors but rather the proportion of total population was less. Census 2000 reflected the relatively low number of births in the late 1920's and early 1930's causing a decline in the 65-to-74 age group during the 1990 to 2000 decade. The U. S. Census Bureau 2000 predicted once baby boomers (born from 1946 through 1964) reached age 65; the numbers would begin increasing. During the 1990's, the most rapid numerical growth for the older population occurred in the oldest old age groups (Riekse \& Hostege, 1996). According to the U. S. Census Bureau 2000 \& 2001, data indicated individuals over 65 years of age found women (20.6 million) outnumbering men (14.4 million).

Over the years, nomenclature definitions identifying those over 65 years of age have changed. The U. S. Census Bureau 1993 
divided the elderly into three age categories that are currently used today. The categories included the young-old, 65 to 74 years, the aged, 75 to 84 years, and the oldest old, 85 years and older. An additional category identified the frail elderly as those individuals 65 years of age or older with physical and or mental disabilities. Finally, an emerging category discussed by Adlers (2003) were people over 100 years of age and over identified as centenarians.

Data indicated the rates of seniors steadily increasing since the turn of the century. In 1900, one in 25 Americans (3.1 million was identified as over 65 years of age). In 1994, one in eight seniors (33.2 million) was over 65 years of age. By 2050, one in five Americans may be seniors. The largest senior growth would occur from baby boomers between the years 2010 and 2030 according to the U.S. Census Bureau, Statistical Brief, 1995. Kockhanek and Bettie (1994) stated life expectancy had seen an improvement since this country was founded. Life expectancy in the 1900's was 47 years, 1950's was 68 years, and 1991 was 76 years. Over the span of 1900 to 1992, life expectancy of men increased from 46 years to 73.2 years while a woman's increased from 48 years to 79.8 years. Rieske and Holstege (1996) claimed women tend to live approximately seven years longer than their male partner. Mortality rates for males are higher than females at all ages (U. S. Census Bureau, 1993). Ethnicity also affected life expectancy. U. S. Census Bureau (1995) Caucasians lived longer than Blacks and both lived longer than Hispanics.

Using Polizzi and Steitz (1998) and Polizzi (2001), Aging Semantic Differential, Millikin (2002) hypothesized senior terminology used for research data collection was a significant determinant that influenced attitude scores. It was concluded that ageist language had an impact.

A lack of knowledge exists about seniors' challenges and needs. A common concern was educating health care providers, family members, educators, counselors, or any individuals involved in working with seniors. Programs designed for seniors and personal needs for seniors needed to be accurately identified to enhance seniors' lifestyles. Knowing the perceived needs and interests of the target population is vital to the success of any program, but especially for senior individuals (Burdman \& Burdman, 1975; Riggs, 1978; Sherron \& Lumsden, 1978).

Several points to consider from Rieske \& Holstege (1996) highlighting the impact of aging on the average citizen included:

- Americans today have more living parents than children;

- more individuals care for elderly relatives and especially their parents;

- women spend 18 years raising their parent(s) versus 17 years raising their children;

- 80 to 90 percent of care for the older family member is provided by the daughter or daughter-in-law; and

- nursing homes provided only five percent of care for older individuals.

From these facts, one needs to consider the impact of growing older in America and what is to come. "With the number and percentage of older people we have today, and when people 65 of age and older outnumber teenagers by more than two to one (as projected by 2025), we have no option but to deal with the realities of an aging America” (Rieske \& Holstege, 1996, p. 18).

\section{Statement of the Problem}

The increasing number of seniors mandates the need to examine the special needs and attributes of senior persons (Coward \& Lee, 1985; Krout, 1986; Bull, 1993). Identifying current trends affecting seniors could shed light on both the social and physical context which impact their daily lives. One must begin looking at current seniors and their perceptions and needs. Numerous programs are available. However, they were designed and implemented by individuals under 65 years of age. We must ask our seniors if these programs are really what they feel are necessary to help them in their daily lives. 
Focus groups were identified as the best method to explore seniors' perceptions regarding their needs as a mobile senior citizen. In addition, focus groups were recommended as the best method to attain an understanding of why and what these individuals really needed. By pursuing these needs, the potential for identifying programs, services, and/or concerns may be more fully addressed. What the "gatekeeper" or program planner sees as the seniors' needs may not be the same as what the senior individuals see as their needs for a better quality of life. Financial problems and misconceptions about community senior services which currently exist and the increasing population growth of seniors need to be addressed before demands on services becomes a major problem, such as, payment of social security benefits, Medicaid funding, nursing home shortages, to name only a few (U.S. Census Bureau 2000, 2001).

It was also important to study the new, "emerging old" or baby boomers who would begin entering the senior age bracket in the year 2011. These individuals would enter their "senior years" with different viewpoints, different perspectives on aging, healthier lived lives, earned more money, and projected to live a longer life span. Due to their lifestyles, baby boomer individuals need to begin addressing their upcoming senior needs and perceptions. By 2030, one out of five citizens will be in the senior age category (U.S. Census Bureau 2000, 2001).

\section{Purpose of the Study}

The purpose of this study was to assess seniors' perceptions of their current health needs and to compare them with baby boomers' perceptions of future health needs as they begin entering the senior age bracket in 2011.

\section{Research Questions}

The following research questions were addressed in this study:

1. What terms reflect your perceived identity in your age group as a senior citizen?

2. What are the current health needs of seniors age 65 and over?
3. What are the perceived health needs of baby boomers for when they begin entering the senior age bracket in 2011?

\section{Need for the Study}

Senior individuals' perceptions of their needs are changing according to the time and place occurring (Rieske \& Holstege, 1996; Smith, 2000). The growing numbers of seniors make understanding seniors' behaviors, knowledge, and attitudes to our best ability imperative in order to meet their actual and projected needs. As the baby boomers come of age, we must be prepared to handle their needs. The decreased population of younger adults, born after 1964 and identified as the baby bust cohort group, will not provide the needed resources to assist the baby boomers. We need to begin immediately looking at trends for the future. Generally all seniors need these issues studied but this study addressed primarily a local Midwest community. Another important factor concerns seniors living in non-metropolitan and rural areas that tend to have more problems relating to health, insurance, and transportation (Ricketts, 1999; Smith, 2000).

\section{Research Design}

A qualitative method of investigation was used as the framework for this study. This approach was necessary to understand seniors' and baby boomers' explicit views in order to avoid misconceptions regarding aging. Data were collected using focus groups with populations of adults as follows: 1) the first group was seniors, 65 years of age and over; 2) second was baby boomers, 39 to 57 years of age; 3 ) data would be collected from four to six focus groups per age group until it became evident that no new information was coming forward. Focus group sessions consisted of five to seven individuals from non-metropolitan areas in each group. One-hour focus group sessions were used.

Locations for senior focus groups were the local Senior Center and a residence. Location for baby boomer focus groups were a Newman Center and a local residence. The setting at each facility was a small, private room. After focus group sessions, participants completed a survey consisting of demographic questions. 
Small focus groups were reported to be an ideal method for gathering accurate information on attitudes, preferences, and knowledge without feeling conflict from participants (Patton, 1980; Cresswell, 1998; McKenzie \& Smeltzer, 2001). Previous research by Krueger (1994), Morgan and Krueger (1993), and Stewart and Shamdasani (1990) also studied concerns with aging populations. These authors identified focus groups as their research method to obtain participant observations, reactions, and personal reflections.

\section{Population and Sample}

Two populations were selected for this study. The first consisted of male and female senior individuals 65 years of age and over and the second consisted of male and female baby boomers aged 39 to 57 years of age who resided in a non-metropolitan community in Illinois. The community's population was 25,168 (U.S. Census Bureau, 2001). The 65 years of age and over population consisted of 1,239 females and 684 males, or a total of 1,923 or 7.6 percent of the population. Further categorizing the seniors, the young old consisted of 838 people, the aged totaled 722, and the oldest old had 363 people. The volunteer sample was identified from the community. The volunteer baby boomers ranged between 39 and 57 years of age and also resided in the community. Participant names were kept anonymous; however, participants were identified by using an alias for the sake of consistency in reporting data.

\section{Data Collection}

Prior to data collection, the researcher asked a colleague as a first step to review and complete a focus group instrument as if that colleague was a member of the intended target group. Various points were included in this initial analysis: 1) appropriateness of title, 2) introductory statement for research purpose, 3) directions, 4) order or grouping of questions to be discussed, 5) appropriateness of questions, and 6) length and method of instrument selection (McKenzie \& Smeltzer, 2001). After a panel of experts reviewed and evaluated focus group topic questions, materials were revised. Pilot studies were then completed.
Focus groups were used to collect the qualitative data and a quantitative questionnaire was completed for demographic status of participants for this study. The description of the data gathering process follows the research moderator for participant discussion posed openended questions with a court reporter transcribing the information. The moderator was allowed only to initiate questions and keep communications flowing equally among all participants. Two audio tape players were used to record communications as a data back up. Two outside observers were used to record facial expressions, hand gestures, and body positions. During focus group discussions, the moderator made notes as necessary to assist in data analysis. At the completion of each focus group, a ten-minute demographic questionnaire was completed. Participants provided volunteer information concerning their demographic background information. Baby boomers had an additional question providing information pertaining to contact with persons 65 years of age and over. Focus groups contained between five to ten participants for each of the group discussions. A thank you note and a five-dollar gift certificate for a local restaurant were provided as token gifts for the participants at completion of the session in appreciation of their time and contribution to the study.

\section{Data Analysis}

Data analysis for this study was obtained from questionnaires, notes, observations, and transcriptions of focus groups. A descriptive method was used to analyze the data. For the type of data studied, Berelson (1952) believed that descriptive analysis was more reasonable than other qualitative methods to communicate the data. The greatest strengths of content analysis method were that they are unobtrusive and can be conducted without disturbing the setting (Marshall and Rossman, 1995).

\section{Delimitations}

"Delimitations address how the study will be narrowed in scope" (Creswell, 1994, p. 110). Delimitations that should be considered when interpreting this study are as follows: 
1. Participants for the study were mobile, community residents. This included no individual living in a nursing home, assisted living facility, or rehabilitation center.

2. Senior participants were accepted at two locations, a local Senior Citizen Center and Senior Heritage Organization, for the focus groups. Baby boomer participants volunteered from one location, Newman Center, for the focus groups.

3. The researcher served as the moderator for each session.

4. Focus groups were small numbers of participants within a time limit of approximately 60 minutes.

5. Due to a particular population bias in the study area, other needs may exist in a different locale where particular services do or do not exist. Participants may not experience or perceive same needs as seniors elsewhere.

\section{Limitations}

"Limitations are defined as conditions that weaken or restrict conclusions that may be drawn from the study" (Cresswell, 1994, p. 110). Limitations that should be considered when interpreting this study are as follows:

1. There may have been volunteer bias in the sample of the study.

2. Participants answering may have been familiar with other participants and felt intimidated to answer honestly or how they truly felt.

3. This study used a sample of convenience with volunteer participants recommended by key informants and participant networking "snowballing effect."

4. Participants may not truly represent the two age groups studied.

5. The open-ended questions may not have measured all variables that may influence a participant's responses within the time frame allowed.

6. Perceptions of participants are their own and may not have reflected what other participants perceived.

\section{Assumptions}

Creswell (1994) described assumptions as basic characteristics that the researchers believed to be true about the study however these assumptions cannot be proven. Assumptions that should be considered when interpreting this study are as follows:

1. Participants represented various social economic status groups of the nonmetropolitan community.

2. Participants were honest and answered questions to the best of their ability in the limited time.

3. All participants understood the questions for discussion in the focus groups.

4. This method was a convenient method for retrieving perceptions from the two distinct groups to understand needs for seniors.

\section{Summary of Related Demographic and Background \\ Characteristics for Senior Focus Group Participants}

A majority of senior focus group participants, 65 years and over, were married or widowed. Participants were comprised of a majority of Whites with Blacks and Hispanics also represented.

Senior gender representation consisted of males and females aged 67 to 92 years of age. The seniors' age categories, the young old, the aged, and the oldest old, rates were consistent with the increase of age statistics that senior population numbers decrease and males decrease.

Participant academic levels of education were from high school through doctoral degrees. As academic levels rose, the percentage of participants rose likewise.

The expectations for all seniors to be retired were not met. Several seniors were employed full-time. As a university community, occupations were affiliated with educational employment. (i.e., librarian, directors, administration, professors/ teachers). Senior retirement ages were varied with the majority retiring at 65 or over. Currently all seniors receive social security. Individuals employed were receiving dual incomes-social security 
and a regular pay check from their current employer.

Contact with individuals under 65 years of age varied within the group. All seniors had some form of contact with individuals under 65 years of age. Approximately three fourths of the seniors had no children and/or grandchildren residing in their homes.

Senior focus group participants had a majority belonging to various organizations. The participants listed 32 distinct organizations.

Senior self-transportation was available by all participants. The mean age of was 77 years.

From a selection of three categories, the participant's rated their health as excellent or fair. Over half of the individuals perceived their health to be fair. All participants had medical insurance while only a portion received dental insurance.

\section{Characteristics for Baby Boomer Focus Group Participants}

Data from the baby boomer focus group indicated individuals ranged from 39 to 57 years. Participants were married, divorced, and never married. Focus groups had a majority of Whites while Blacks, Hispanics, and Other nationalities comprised the remainder. Rural Illinois adults indicated a large variation with Whites, and limited variation of Blacks and Other.

Baby boomer gender in the focus groups consisted of males and females aged 39 to 57 years. Distribution was equally divided into 39 to 44 years, 45 to 50 years, and 51 to 57 years. Males comprised half of the 51 to 57 year group while females were equally divided into the three categories.

Baby boomer education levels were from high school through doctoral degrees. Master degree's ranked highest, followed by bachelor degree, technical training and junior college.

The majority of baby boomers were employed. Limitations of employment were due to participant disabilities. Occupations were administrators, secretaries, professors/teachers, professionals, researchers, directors, social workers/case managers, technicians, ministers, and maintenance personnel.

Reported retirement estimates ranged from 55 years to 100 years. The majority of baby boomers planned retirement between ages 59 and 66 years.

Baby boomer data on children and grandchildren were limited. Baby boomers children living at home were greater than grandchildren living in the baby boomer's home.

Baby boomers reported membership in various organizations. They listed 37 distinct organizations.

Contact with individuals over 65 years of age varied within the group. Most baby boomers had some form or other of contact with individuals over 65 years of age.

Many baby boomers responded they expected to receive social security benefits. Smaller numbers indicated they did not expect to receive social security.

Baby boomers self-transportation was available to the majority of participants. Handicap participants needed transportation assistance.

Participant's perceptions of how they would rate health included excellent, fair, and poor receiving no marks. Most individuals indicated excellent. Baby boomers reported most had medical insurance but fewer had dental insurance.

Research Question One: What terms reflect your perceived identity in your age group as a senior citizen? The term of choice for individuals 65 years of age and over was identified as "senior" or "senior citizen." The seniors' second choice was "mature citizen" or "mature." The baby boomers' second choice was "elders" and "elderly." 
Research Question Two: What are the current health needs of seniors age 65 and over in retirement?

Seniors' concerns were similar to baby boomers' concerns about health care needs. Finances play a critical role in the perception of health needs. Misconceptions about health care services, prescription drugs, or accessing health services were held by current seniors.

Research Question Three: What are the perceived health needs of baby boomers when they begin entering the senior age bracket in 2011? The same conclusions for research question two can be made for research question three. Finances play a critical role in the perception of health needs. Misconceptions about health care services, prescription drugs, or accessing health services were held by current baby boomers.

\section{Conclusions}

Based on the results of this study, the following conclusions can be made:

1. Seniors and baby boomers in this sample are alike in their concerns about health care needs.

2. In this sample, finances play a critical role in the perception of health needs.

3. Misconceptions about health care services, prescription drugs, or accessing health services abound in both sample groups.

Findings and Discussion

Findings were separated into eight themes and sub-categories from data acquired. It became evident that all categories were interwoven in some aspect or another. Themes were treated as separate categories during the analysis for this study. The senior and the baby boomer focus group themes and sub-categories were as follows in Table 1.

Table 1

Perceived Health Needs in Retirement Years 65 and Over: Themes and Categories

\begin{tabular}{|c|c|c|c|}
\hline Themes & Categories & Seniors & $\begin{array}{c}\text { Baby } \\
\text { Boomers }\end{array}$ \\
\hline Prescription Drug Plan & Prescription drugs & $\mathrm{X}$ & $\mathrm{X}$ \\
\hline Insurance & $\begin{array}{l}\text { Pension/Insurance Plans } \\
\text { No Coverage } \\
\text { Medicare/Medicaid } \\
\text { Supplemental Insurance } \\
\text { Social Security Benefits }\end{array}$ & $\begin{array}{l}X \\
X \\
X \\
X \\
X\end{array}$ & $\begin{array}{l}X \\
X \\
X \\
X \\
X\end{array}$ \\
\hline Government Programs & $\begin{array}{l}\text { Universal Health Programs } \\
\text { International Health } \\
\text { Cutback on Programs } \\
\text { Government Spending } \\
\text { Taxpayer Rights }\end{array}$ & $\begin{array}{l}X \\
X \\
X \\
X \\
X\end{array}$ & $\begin{array}{l}X \\
X \\
X \\
X \\
X\end{array}$ \\
\hline Transportation & $\begin{array}{l}\text { Location } \\
\text { Mode } \\
\text { Time }\end{array}$ & $\begin{array}{c}X \\
X \\
N / R\end{array}$ & $\begin{array}{l}X \\
X \\
X\end{array}$ \\
\hline $\begin{array}{l}\text { Accessibility of Services/ } \\
\text { Providers }\end{array}$ & Access (Pro’s and Con’s) & $\mathrm{X}$ & $\mathrm{X}$ \\
\hline Retirement Planning & $\begin{array}{l}\text { Retirement Savings } \\
\text { Self-sufficiency } \\
\text { Medical Insurance } \\
\text { Long Term/Retirement Homes } \\
\text { Assisted Living/Retirement }\end{array}$ & $\begin{array}{l}X \\
X \\
X \\
X \\
X\end{array}$ & $\begin{array}{l}X \\
X \\
X \\
X \\
X\end{array}$ \\
\hline Attitudes & $\begin{array}{l}\text { Attitudes } \\
\text { Activities }\end{array}$ & $\begin{array}{l}X \\
X\end{array}$ & $\begin{array}{l}\mathrm{X} \\
\mathrm{X}\end{array}$ \\
\hline
\end{tabular}




\begin{tabular}{|l|l|c|c|}
\hline \multicolumn{1}{|c|}{ Themes } & \multicolumn{1}{|c|}{ Categories } & Seniors & $\begin{array}{c}\text { Baby } \\
\text { Boomers }\end{array}$ \\
\hline & Employment & $\mathrm{X}$ & $\mathrm{X}$ \\
& Current Events & $\mathrm{X}$ & $\mathrm{X}$ \\
& Adopt a Senior & $\mathrm{X}$ & $\mathrm{N} / \mathrm{R}$ \\
\hline Rating One's Health/ & Existing Medical Problems & $\mathrm{X}$ & $\mathrm{X}$ \\
Recommendations & Eating Healthy/Diet & $\mathrm{X}$ & $\mathrm{X}$ \\
& Exercise/No Smoking & $\mathrm{X}$ & $\mathrm{X}$ \\
& Stress & $\mathrm{N} / \mathrm{R}$ & $\mathrm{X}$ \\
\hline
\end{tabular}

$\mathrm{N} / \mathrm{R}=$ No response for category

Seniors did not discuss two sub-categories that were discussed by baby boomers (see Table 1 ). The sub-categories were under 1) a Transportation theme, "Time" and 2) Rating One's Health theme, "Stress." Likewise, baby boomers did not discuss a sub-category in the Attitudes theme, “Adopt a Senior" category.

The themes and sub-category sections were derived from the data from the focus group sessions. Participant's experiences were used to illustrate each theme analyzed with direct quotations from the focus group sessions to answer the research questions. Seniors were able to identify and understand their health needs during retirement years. As BB-Mabel concluded, "This was an eye opening experience today." In this researcher's opinion, baby boomer's would talk the talk, but could not walk the walk.

\section{Theme 1: Prescription Drug Plans}

Finding: There was a main concern from seniors and baby boomers as to the future of prescription drug payments and escalating costs. Discussion: This was a common concern. Participants discussed the problems associated with the high costs associated with minimal or no prescription coverage. Discussions continued with participants who had insurance plans that covered portions of their drugs. Participants discussed the possibilities of mail order drugs, generic drugs, and foreign country drug supplies. Seniors with no insurance often needed to make difficult decisions to buy drugs recommended by their doctors, to pay utility bills, to put food on their table, or to eliminate taking the medications. Focus group participants mentioned two themes including (1) Prescription
Drug Plans and (2) Insurance. Baby boomers suggested needing some type of "checks and balance" for controlling pharmaceutical costs. Seniors recommended the need for a plan that would provide financial assistance for prescriptions.

\section{Theme 2: Insurance}

Finding: Insurance of various types was of concern. Discussion: Data from participants recommended that seniors have some type of pension plan or supplemental insurance to help provide for their needs during retirement years. Medicare entitlement money provisions were not enough to cover most expenses because of high co-payments. Individuals without coverage would generally have to go without the necessary care. Wong (1998) stated senior individuals required extra medical services. American Association of Retired People AARP, Roper Starch Worldwide (1999) found when baby boomers retire, there would be no one-sizefits-all for retirement solutions.

All senior participants received social security. They questioned how long the benefits would continue. Weller (2000) and Love (1999) discussed the effect of raising the retirement age gradually to 67 years.

The lack of future funding for Social Security benefits was also a concern of the baby boomers for retirement. Baby boomers revealed concerns about difficulties in getting insurance coverage especially with pre-existing conditions, locating doctors who accept Medicaid or Medicare patients, and costs for additional coverage. Baby boomers and seniors indicated, "If you are healthy, you are in good shape. If you are not 
healthy, you are going to have financial problems.” Cassett (2001) examined the positive side of living a longer life expectancy while also addressing the risk factors associated with chronic diseases.

\section{Theme 3: Government Programs}

Finding: The government should assist with some form of a universal health plan for seniors. Discussion: Seniors and baby boomers suggested some type of universal coverage was necessary. To some extent, participants believe that all people are currently covered in limited emergency situations. The level of your coverage depends on your insurance plan and premium payments.

Seniors and baby boomers discussed international health care and questioned why those countries could provide the services while our government could not afford similar coverage.

Government dependence should not occur for our seniors, rather basically their children should provide or contribute to the care of their senior family members. Baby boomer data concerning community provisions recommended greater involvement with senior services since every person has a voice in the local government. This is where our voices need to be heard and appropriate provisions for seniors are mandated. A community consultant for heath needs should be available for guidance. Wong (1998) suggested baby boomers when they become seniors would be a politically powerful group because of their increasing size. They will represent twenty percent of our population by 2030.

\section{Theme 4: Transportation}

Finding: Transportation issues were not viewed as critical concerns. Discussion: Seniors and baby boomers indicated transportation was available. Travel time may be longer or inconvenient but it is accessible. Proximity to events is merely a short distance with few parking problems or individual problems with night driving. Transportation methods available were buses, senior van services, taxis, friends, themselves, or with-in walking distance. Cost was minimal for senior van services, if planned twenty-four hours in advance. Carbondale Illinois Resource Guide (2003) provided information regarding the various types of transportation available. Egyptian Agency on Aging Resource and Caregiver Guide (2003) provided information for further senior services.

\section{Theme 5: Accessibility of Services/Providers \\ Finding: Concerns existed regarding} accessibility of services in this non-metropolitan location. Discussion: Accessibility of services or doctors was reported both in a positive manner and negative manner depending on the health problem. Carbondale, being a nonmetropolitan area has limited specialists. Specialists are available within a two and a halfhour drive depending on individual needs. Participants indicated access has improved steadily over the years. For the most part, Carbondale met with the majority of participants' approval.

Handicapped individuals and seniors may be similar because doctors have a difficult time addressing special health problems. Gatz and Pearson (1988) indicated when physicians have a negative attitude, conditions may be left untreated. Handicapped individuals indicated they do not perceive any special changes when they reach retirement because they have had to make adjustments all their lives, so in retirement it would not be any different.

A positive access finding included the one-onone, closeness, or friendships that develop between the doctor and patient relationship in this community. Participants appreciate this constant interaction.

\section{Theme 6: Retirement Planning}

Finding: The importance of retirement planning conflicted with the ability to actually contribute to such a retirement plan. Discussion: Participants were aware of the necessity for having retirement savings but being alone and being able to save for a retirement were two different matters. Butler (2000) indicated baby boomers are a generation at risk because individuals are not saving for retirement. Selfsufficiency was highly recommended by senior 
focus group participants. Each individual needs to recognize and accept responsibility for life decisions. Seniors advised no matter how small a salary you make, always put some money away for your retirement. Findings indicated the need for baby boomers to invest in a finance class to understand how to plan for their futures. American Association of Retired People AARP, Roper Starch Worldwide (1999) found when boomers retire, there would be no one-size-fitsall for retirement solutions or feasibility costs. Baby boomers would be presenting a new perspective to retirement.

Long-term care and/or retirement insurance prior to retirement were also indicated by seniors because of the escalating costs. The earlier the age at which long-term care insurance is acquired the lower the cost. Baby boomers tended to avoid or be in denial that retirement is only a few years away. Data indicated their knowledge was limited concerning assisted living facilities and nursing homes.

Ervin (2000) forecasted fourteen points for baby boomers to think about for retirement planning. Several points were covered under this theme such as, long-term care, caregivers, senior care, and nursing home alternatives.

\section{Theme 7: Attitudes}

Finding: Having a positive attitude was equated with living a healthy life. Discussion: Attitudes were regarded as a very important topic. A negative attitude would cause one to deteriorate or decline quickly.

Kupetz (1993) and Lifshitz (2002) described how attitudes affect the aging process either positively or negatively. Individuals need to begin learning the knowledge concerning our body's aging lifecycle. Langer (1999) discussed modifying negative attitudes while Krathwohl, Bloom, and Masia (1964) recommended the need for positive attitudes.

Activity was found to be a significant health factor whether one is a senior or a current baby boomer. Walking, talking, jet skiing, driving, reading, dancing, playing cards were necessary activities for seniors. Keeping the mind stimulated was an important part of staying healthy.

Some participants recommended seniors should always work, while others enjoyed not having to work. Some people were required to take retirement due to job requirements. Butler (2000) found longer life expectancies were causing older workers to need to remain employed in the workforce for an increased amount of time. Other individuals have the option to work as long as they so choose. Employment overlaps with the sub-category, Activity. It is important for people of all ages to remain active in order to keep the mind and body stimulated.

Senior data indicated the need to always stay informed of current events in order to know what is taking place locally, nationally, or world wide because everyone is affected. Information is constantly changing so it is important to be aware of the changes. A final senior participant sub-category suggestion was to "adopt a senior." Seniors have acquired and experienced vast amounts of information that younger people need to learn. The socialization process would be an equally important factor for the participants.

\section{Theme 8: Health Ratings and Recommendations}

Finding: Baby boomers rate their health entering retirement in a healthier state than current retirees. Discussion: The senior participants' health was ranked on a scale from one to ten; the average ranking for seniors was approximately a seven while baby boomers' average rank was approximately at seven and a half. Referring back to the Demographic Study, more seniors ranked their health as fair versus baby boomers who ranked their health as excellent. This correlates with the seniors having a lower than average rank than the baby boomers slightly higher rank. Federal Interagency Forum on Aging-Related Statistics (2000) indicated 72 percent of seniors ranked their health status as good, very good, or excellent. Senior data indicated a majority of participants had positive attitudes towards their health and overlooked the normal aging 
problems. Seniors and baby boomers both agreed upon the necessity of eating healthy diets with proper nutrition, exercise, and no smoking. Federal Interagency Forum on Aging-Related Statistics (2000) indicated only twenty-one percent of seniors ranked their diets as good. Only baby boomers included the one topic attempting to eliminate stress. This was related to raising families, working, and paying bills. Foot (1996) discussed: 1) higher activity levels over predecessors and 2) social and economic challenges as having resulted in the promotion of physical activity as a powerful tool for managing stress, depression, and emotional health. Foot and Stoffman (1997) substantiated that changing social norms have fostered the trend towards higher levels of physical activity.

Final Finding: Health needs overlap in all phases for senior retirement years. Discussion: All data collected were from the nine focus group sessions. Participants related personal experiences, friends' experiences, or commonly known knowledge to determine the health needs in retirement. The exchange of ideas was intense at times when participants were explaining their particular viewpoints. By using the focus group format, participants were able to share experiences as well as have an "eye opening experience" regarding retirement years. In the researcher's opinion, until participants became involved in the health needs in retirement discussion, only minimal thoughts occurred previously.

\section{Recommendations for Future Focus Group Sessions}

Researcher and key informant, observers, and court reporters should make a concerted effort to establish an acceptable climate in which the participants feel free to express openness without judgmental criticisms. The following recommendations are made based upon the findings in this study for future focus group sessions.

1. Ask key informant to assist in recruiting participants, if on a walk-in basis. If participants are regular clients at a facility, attend a week prior to make social contacts and make several announcements of upcoming focus groups so clients are more aware of the situation. Have key informant identify several participants who have outgoing personalities to help draw in further participants.

2. Recommend 4 to 6 participants per focus group session. Limiting the number of participants allows all participants to be able to voice their opinions.

3. Participants that were previously called, sent letters, and reminded need to be reminded again on the day of the meeting.

4. If any inclement weather is predicted for a scheduled date, reschedule the focus group session. Seniors will not travel during inclement weather (i.e., snow, ice, rain).

5. Check the room location prior to session to know noise levels, cooling or heating system, and room arrangements. Select an environment conducive to an informal, relaxed atmosphere that helps to provide a bonding of the participants. Room selections may include a small private room, a library, a living room, business office, home dining room, or what is most appropriate. Entrances and exits must be easily accessible. If necessary, transportation should be provided.

6. For senior participants, the room must be in close proximity to the entrance because some may have limited walking abilities.

7. Depending on the time frame for participants, the demographic survey may be completed prior to the session for individuals on a tight schedule.

8. Have tapes available to run the entire length of a session without having to stop and flip over.

9. Participants should initiate conversation each time by stating their alias name and speak in a loud, clear voice. Begin with casual conversation to break the ice, especially if participants do not know each other.

10. Appreciation expressed through a restaurant token gift was received well by all participants. Cost for a token gift was $\$ 5$ for each gift. Participants leaving with a reward is an important factor in establishing good will towards participation on a similar study. 


\section{Recommendation for Health Educators}

Based on the results of this study, the following recommendations are made. It is recommended that health educators offer the following:

1. "Eye opening” experiences for baby boomers. Seminar sessions organized for middle aged individuals to plan for retirement years. Programs may be conducted through local health department agencies, insurance companies, employers, health care systems, hospitals, local businesses, retirement facilities, state government, local governments, churches, or other groups working to establish effective retirement education.

2. Knowledge and understanding of the aging process should be an ongoing process through the various schools' curricula, elementary through college and other appropriate health agencies, i.e., AARP, agencies on aging, medical health agencies community colleges, governmental agencies. Brochures may be distributed to key areas where baby boomers frequent to read and discuss. i.e., dental reception offices, doctor offices, hospital waiting rooms, hair salons, beauty shops, or places open for discussions and reading among worker and clients waiting for appointments and during appointments. Use these opportunities to stimulate discussions about aging. The key is to open the door graciously when entering into the world of retirement.

3. Education is needed for baby boomers and seniors that would provide an awareness of Medicare and supplemental insurance, prescription plans, and other needs in retirement. Excellent resource would be an on-line service called National Council on Aging located at www.ncoa.org. Explore the Internet.

4. Community programs for retirement planning should be developed which involve the senior community. Programs may be promoted through radio advertisements, cable television, newspaper articles/ads, billboards, magazines, flyers, or whatever a local community, county, state, or federal government may afford.
5. Health educators will need to be given further training in order to develop skills in planning, implementing, and evaluating programs that involve senior centers, assisted living facilities, nursing homes, and other facilities.

6. Health plans should be developed concentrating on increasing personal responsibility for individual health, coping strategies, and enhancing their personal health and attitudes.

7. Health educators should develop multiple plans to stress the importance of nutrition, exercise, weight reduction, and stress reduction to help maintain one's health for life.

\section{Recommendations for Seniors and Baby Boomers}

Five recommendations for seniors and baby boomers evolved from this study. They included the following recommendations:

1. Have a positive attitude. Participants' stressed the need for a positive attitude and felt attitude directly affected the quality of one's health and life.

2. Seniors and baby boomers both cited the need for proper nutrition, exercise, and avoiding smoking as recommendations for staying healthy.

3. Seniors and baby boomers need to be challenged not only physically but also mentally as a means of staying healthy. Participants recommended exercising, not only the body but also the brain, to ensure the ability to stay active and healthy in later years.

4. One needs to eliminate or reduce stress. Baby boomers recommended stress reduction as a big factor in staying mentally healthy.

5. Always think ahead and be prepared for your retirement. Seniors and baby boomers recommended beginning to plan early for retirement. They felt that unexpected circumstances could often "waylay" retirement plans. By beginning to think about retirement during one's younger years, and developing a reasonable plan for 
retirement, they felt the quality of life in retirement could be assured.

\section{Future Research}

The following recommendations may be developed for future research concerning senior populations.

1. Select seniors and baby boomers located in rural communities a minimum of 25 miles away to reduce the number of university or university affiliated participants with state insurance plans.

2. Complete follow-up focus groups with the same baby boomer participants one year later to determine if any changes occurred towards retirement planning and their health needs.

3. Develop the eight themes into a quantitative survey for a larger sampling of the population including metropolitan, nonmetropolitan, and rural locations to compare similarities and differences.

4. Compare seniors with centenarian's perceptions of living a longer life span and how to better prepare for the retirement years.

\section{Epilogue}

As a baby boomer, I would like to voice some personal thoughts and opinions. We need to face reality. We are aging in a different world and at a different pace. We set ourselves in denial that we are getting older. We generally stay healthier because of our active lifestyle and years of exercise gyms. We are living longer. Since we are living longer, we need to realize our retirement age is going to be later ... if we ever retire. Have we planned for our future and retirement?

Chronic diseases are going to become more prevalent because of increased life spans. Ratios of men to women will change. Costs of living will continue to rise. Birth rates have decreased which in turn will affect the social security funding. We need to seriously take a look at ourselves and reflect about our life.

\section{References}

Adlers, L. P. (2003). Centenarians: The bonus years. Retrieved March 28, 2002, from http://www.adlercentenarians.com

American Association of Retired People AARP. (1999). Baby boomers envision their retirement: An AARP segmentation analysis. Roper Starch Worldwide. Retrieved March 29, 2003, from: http://research.aarp.org/econ/boomer_seg.pdf

Berelson, B. (1952). Content analysis in communication research. Glencoe, IL: Free Press.

Bull, C. N. (1993). Aging in Rural America. Newbury Park, CA: SAGE Publications, Inc.

Burdman, R., \& Burdman, G. D. (1975) The media and health needs of the elderly. Health Education, 6(4), 14-15.

Butler, R. N. (2000). The realities of aging. Geriatrics, 55(5), 3-4. Carbondale Government and Information. Retrieved May 15, 2003, from: http://www.pe.net/ rksnow/ilcountycarbondalegov.htm

Casset, C. K. (2001). Successful aging: How increased life expectancy and medical advances are changing geriatric care. Geriatrics, 56(1), 35-40.

Coward, R. T., \& Lee. G. R. (Eds.). (1995). The elderly in rural America. Washington, D.C.: American Association of Retired Persons (AARP), Public Policy Institute.

Creswell, J. W. (1994). Research design. Qualitative and quantitative approaches. (2nd ed.). Thousand Oaks, CA: Sage Publications, Inc.

Creswell, J. W. (1998). Qualitative inquiry and research design. Choosing among five traditions. Thousand Oaks, CA: Sage Publications, Inc.

Egyptian Area Agency on Aging. (2002). Resource and Caregivers Guide. Carterville, IL: Author.

Ervin, S. L. (2000). Fourteen forecasts for an aging society. The Futurist, 34(6), 24-28. 
Federal Interagency Forum on Aging-Related Statistics.(2000). Older Americans 2000: Key indicators of well-being. Data Dissemination Branch of the National Center on Health Statistics. Retrieved March 1, 2003, from http://www.agingstats.gov/chartbook2000/ordercopy.html

Foot, D. K., \& Stoffman, D. (1997). Progress in prevention. Cohort profiles. Canadians Fitness and Lifestyle Research Institute, Bulletin no.18. Retrieved March 26, 2003, from http://www.cflri.ca/pdf/e/pip18.pdf

Gatz, M., \& Pearson, C. G. (1988). Ageism revised and the provision of psychological services. American Psychologist, 43, 143-148.

Kochanek, K. D., \& Bettie, M. A. (1994). Advance report of final mortality statistics report (December). Hyattsville, MD: National Center for Health Statistics.

Krathwohl, D. R., Bloom, B. S., \& Masia, B. B. (1964). Taxonomy of educational objectives: Handbook II, The affective domain. New York, NY: David McKay.

Krout, J. A. (1986). The aged in rural America. Westport, CT: Greenwood Press.

Krueger, R. A. (1994). Focus groups: A practical guide for applied research (2nd ed). Thousand Oaks, CA: Sage Publications, Inc.

Kupetz, B. N. (1993). Bridging the gap between young and old. Children Today, 22, 10-13.

Langer, N. (1999). Changing youngsters' perceptions of aging: Aging education's role. Educational Gerontology, 25, 549-554.

Lifshitz, H. (2002). Attitudes toward aging in adult and elderly people with intellectual disability. Educational Gerontology, 28, 745-759.

Love, A. A. (1999). We'll all be working longer. Social security retirement age to be 67. Retrieved May 24, 2003, from http://www.analyticrehab.com/dec1999.htm

Marshall, C., \& Rossman, G. (1989). Designing qualitative research. Newbury Park, CA: Sage.

McKenzie, J. F., \& Smeltzer. (2001). Planning, implementing, and evaluating. Health promotion programs. A primer. Needham Heights, MA: Pearson Education Company.

Millikin, R. J. (2002). Attitudes toward the elderly: Identifying problematic usage of ageist and overextended terminology in research instructions. Educational Gerontology, 28(5), 367-378.

Morgan, D. L., \& Krueger, R. A. (1993). When to use focus groups and why. In D. L. Morgan (Ed.), Successful focus groups: Advancing the state of the art. Newbury Park, CA: Sage Publications, Inc.

Patton, M. Q. (1980). Qualitative evaluation methods. Beverly Hills, CA: Sage Publications, Inc.

Polizzi, K. G. (2001). Assessing attitudes toward the elderly: A refinement of the aging semantic differential. Manuscript submitted for publication.

Polizzi, K. G., \& Steitz, J. A. (1998). Examining the aging semantic differential: Suggestions for refinement. Educational Gerontology, 24(2), 207-223.

Ricketts, T. C. (1999). Rural health in the United States. New York, NY: Oxford University Press.

Riekse, R. J., \& Holstege, J. (1996). Growing older in America. St. Louis: McGraw-Hill.

Riggs, R. S. (1978). Perceived health needs/problems/interests of the aged. Health Education, 9, 3.

Sherron, R. H., \& Lumsden, D. B. (1978). Introduction to educational gerontology. Washington, D.C.: Hemisphere.

Smith, O. J. (2000) Aging in America. (edited in Pipher, M.). (1999). Another country: Navigating the emotional terrain of our elders, New York: Riverhead Books, New York: H.W. Wilson Company.

Stewart, D. W., \& Shamdasani, P. N. (1990). Focus groups theory and Practice. Newbury Park, CA: Sage Publications, Inc.

U.S. Census Bureau. (1993). Current Population Reports, Special Studies: (P23-178RV), Sixty-five plus in America. Washington, D.C: U.S. Government Printing Office.

U.S. Census Bureau, Statistical Brief. (1995). Sixty-five plus in the United States. Retrieved March 1, 2003, from Economics and Statistics Administration, U.S. Department of Commerce from http://www.census.gov/population/socdemo/statbriefs/agebrief.html

U.S. Census Bureau 2000. (2001). The 65 years and over population: 2000. Census Bureau 2000 Brief, C2KBR/01-12, Washington, D.C. U. S. House of Representatives Report. (1988). 
Weller, C. E. (2000). Raising the retirement age. The wrong direction for social security. Economic Policy Institute, September 2000 Briefing Paper. Retrieved May 19, 2003, from http://www.epinet.org/printer.cfm?id=842\&content type=

Wong, M. (1998). Demography. Retrieved March 15, 2003, from http://www.chass.utoronto.ca/ reak/ssc/dem_rev.htm

\section{Acknowledgements}

Dr. Sandra Nagel Beebe completed her Doctorate of Philosophy in Health Education in December, 2003. This article was derived from the research conducted from her dissertation under the direction of Chair, Dr. Mark Kittleson and four committee members at Southern Illinois University Carbondale.

Author Information

Sandra Nagel Beebe, RDH, PhD

Clinical Instructor Dental Hygiene

Health Care Professions, ASA, MC 6615

Southern Illinois University Carbondale

Carbondale, IL 62901

Ph. 618-453-7202

Fax. 618-453-7020

E-Mail: sbeebe@siu.edu 